\title{
Improving the Performance of a Real High Voltage Network in the Casablanca Region
}

\author{
A. Belfqih, \\ F. El Mariami \\ ENSEM, Hassan II University \\ BP.8118, Oasis Casablanca
}

\author{
H. Medromi, \\ J. Boukherouaa \\ ENSEM, Hassan II University \\ BP.8118, Oasis Casablanca
}

\author{
N. Belaguide, \\ A. Sayouti \\ ENSEM, Hassan II University \\ BP.8118, Oasis Casablanca
}

\begin{abstract}
In this paper, it proposes to develop the application to calculate the Load flow in order to control the violation of nodal voltages limits of the network and the exceeding in power limit of transport lines. This method is applied to a real grid with 24 nodes in Casablanca. We have expanded our work by detecting the critical node and injecting FACTS to keep the network in good operating conditions.
\end{abstract}

\section{Keywords}

load flow, Newton-Raphson, static compensator of reactive power, FACTS Transmission System Alternating Current.

\section{INTRODUCTION}

The growing development of the Moroccan industrial sector, the evolution of the national electricity grid and rural electrification rate reached 97.4 in 2011 thanks to new strategies for design and operation. And later fast growth in demand for electrical energy which required the entry into service of new power plants and energy exchange between neighboring countries by international interconnections hence the need to strengthen the transmission system while respecting safety regulations in force.

This growing demand for energy and structural complexity are based on current problems in online conduct which leads to the weakening of the power grids and subsequently unable to maintain their stability.

The compensation of reactive power for holding the voltage and enhancing transmission capacity of the lines have become indispensable for the maintenance of the stability of the network, so the transmission systems are used to improve the stability of the grids, to increase transmission capacity of transport lines and to damp the oscillations of power. These devices operate on the voltage and / or impedance of the line by injecting the necessary amount of active power and / or reactive. FACTS are divided into 3 types:

Parallel FACTS: The idea is to provide or absorb reactive power to alter the natural characteristics of the lines in order to make them more compatible with the load. In steady state, the reactive compensation is used to maintain the voltage at the nodes. In transient state, the shunt devices provide a dynamic voltage control to improve transient stability and to damp the power oscillations. Some models of parallel FACTS are the SVC (Static VAR Compensator), TSC (Thyristor Switched Capacitor) and STATCOM (Static Compensator).

Serial FACTS: These devices are the evolutions of serial fixed capacitor. They usually act by inserting a capacitive voltage on the transport line which compensates for the inductive voltage drop. They also modify the effective reactance of the line. The inserted voltage is proportional and perpendicular to the current flowing in the line. Types of series FACTS are TCSC (Thyristor Controlled Series Capacitors) and SSSC (Static Synchronous Series Compensator)

Hybrid FACTS : Hybrid FACTS devices can act on one of the three parameters determining the power transmitted in a line (voltage, impedance and angle) by a combination of both types of devices (shunt and series), it is possible to obtain hybrid devices able to control simultaneously all different variables mentioned above. The main types are the UPFC (Unified Power Flow Controller), the IPFC (Interline Power Flow Controller) and TCPAR (Thyristor Controlled Phase Angle Regulator) [1].

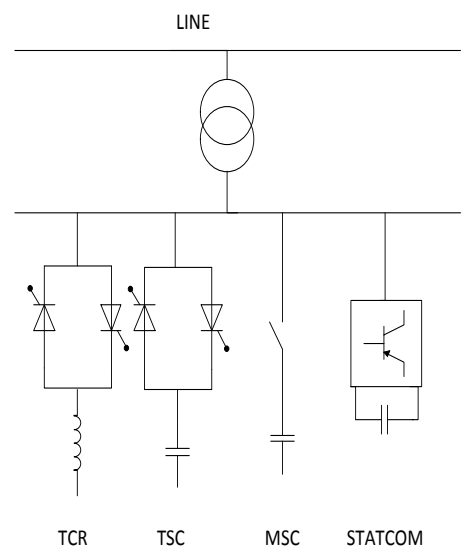

Fig1: parallel FACTS

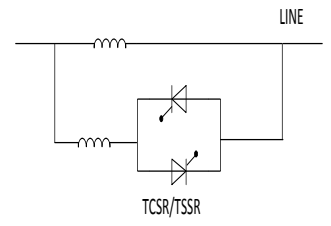

Fig2: serial FACTS TCSR 


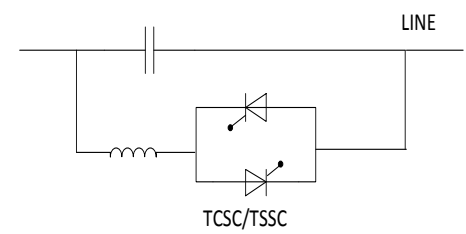

Fig 3: series FACTS TCSC

\section{PRESENTATION OF THE NETWORK OF THE REGION OF CASABLANCA}

The transmission and subtransmission system $225 \mathrm{kV}$ is represented by the network shown in Figure 5, the network composes of 24 nodes with 6 nodes generation, the other nodes are loads (system data are from the year 2012).

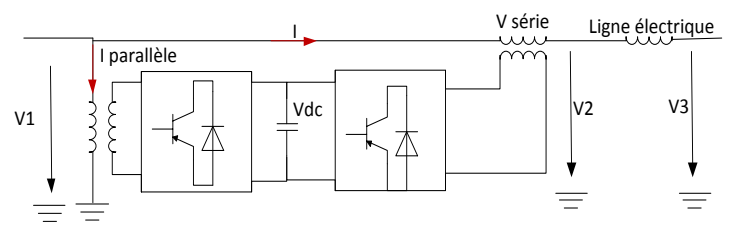

Fig4: hybrid FACTS UPFC

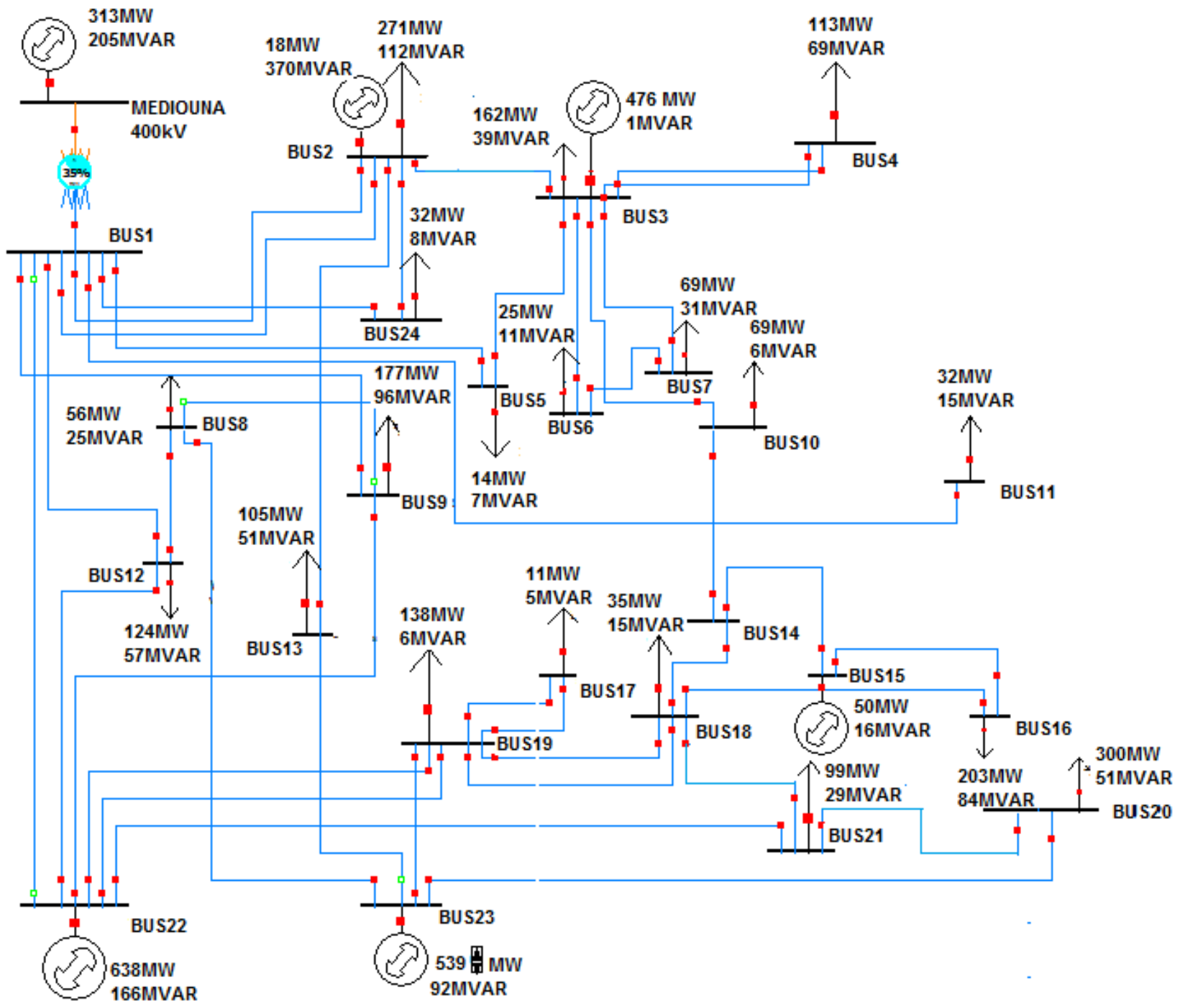

Fig 5 :Network $225 \mathrm{kV}$ of the region of Casablanca 


\section{RESAULT OF LOAD FLOW}

The results of the calculation of load were calculated by the Newton-Raphson method.

Table1: Results of load flow

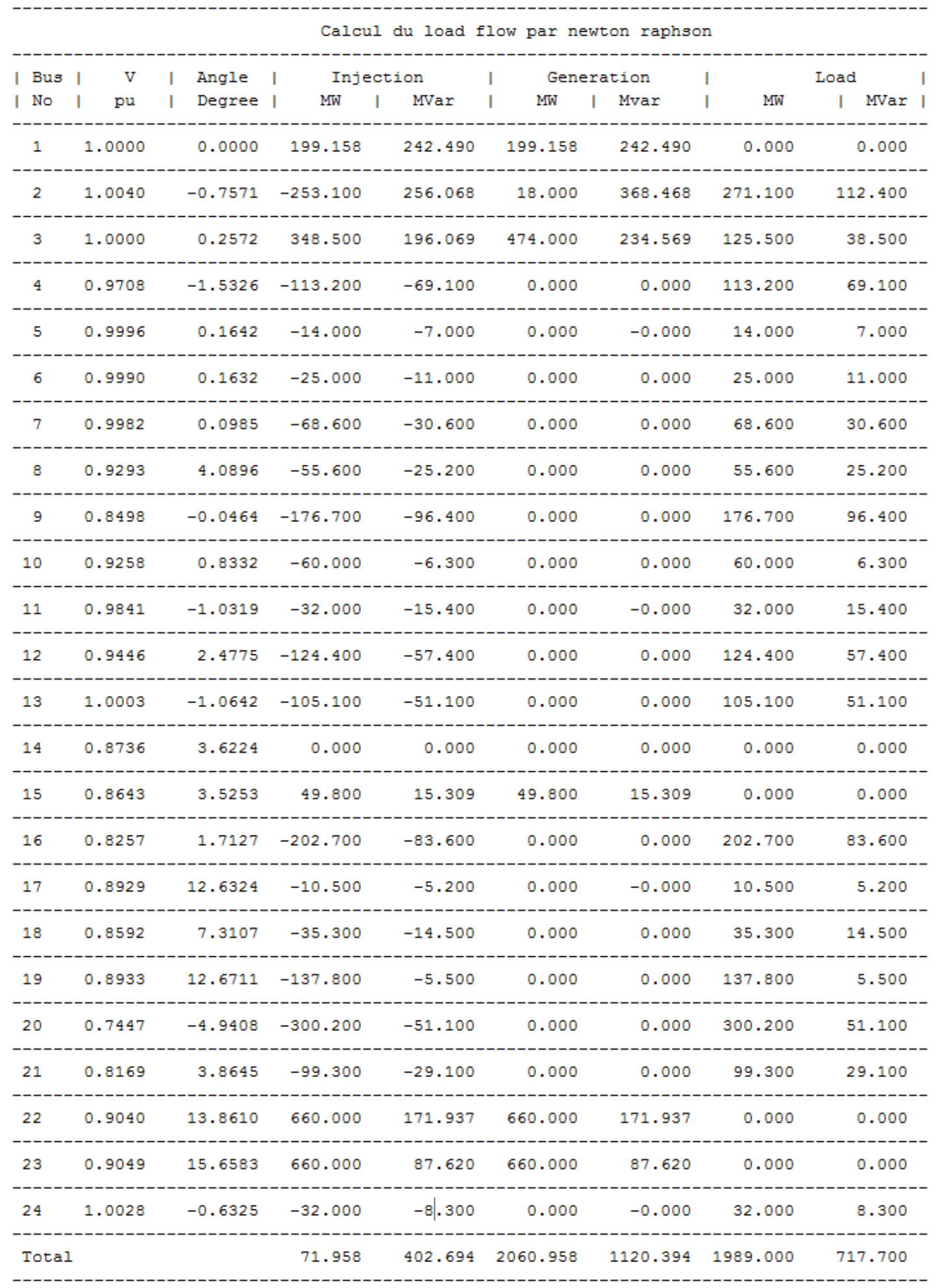


Powers transited through transport lines are as follows:

Table2: Parameters and transited power of transport lines

\begin{tabular}{|c|c|c|c|c|c|c|c|}
\hline Line & From Bus $\mathrm{N}^{\circ}$ & To Bus $\mathrm{N}^{\circ}$ & $\mathrm{R}(\mathrm{pu})$ & $\mathrm{X}(\mathrm{pu})$ & $\mathrm{C}(\mathrm{pu})$ & $\begin{array}{l}\text { S Lim } \\
\text { (MVA) }\end{array}$ & $\begin{array}{l}\text { S Tansit } \\
\text { (MVA) }\end{array}$ \\
\hline L1 & 2 & 1 & 0.00193 & 0.01185 & 0.20039 & 301.0 & 135.1 \\
\hline $\mathrm{L} 2$ & 2 & 1 & 0.00193 & 0.01185 & 0.20039 & 301.0 & 135.1 \\
\hline L3 & 1 & 5 & \begin{tabular}{|l|}
0.00300 \\
\end{tabular} & \begin{tabular}{|l|}
0.01699 \\
\end{tabular} & \begin{tabular}{|l|}
0.02763 \\
\end{tabular} & \begin{tabular}{|l|}
301.0 \\
\end{tabular} & \begin{tabular}{|l|}
39.5 \\
\end{tabular} \\
\hline $\mathrm{L} 4$ & 9 & 1 & 0.01985 & 0.12774 & 0.03706 & 301.0 & 117.2 \\
\hline L5 & 1 & 11 & 0.01774 & 0.06392 & 0.12352 & 187.0 & 36.1 \\
\hline L6 & 12 & 1 & 0.00373 & 0.02406 & 0.03817 & 301.0 & 285 \\
\hline L7 & 1 & 24 & \begin{tabular}{|l|}
0.00166 \\
\end{tabular} & 0.01106 & \begin{tabular}{|l|}
0.02138 \\
\end{tabular} & \begin{tabular}{|l|}
301.0 \\
\end{tabular} & \begin{tabular}{|l|}
119.6 \\
\end{tabular} \\
\hline L8 & 3 & 2 & 0.00336 & 0.01692 & 0.02863 & 301.0 & 46.1 \\
\hline L9 & 13 & 2 & 0.00086 & 0.00554 & 0.00954 & 350.0 & 117.3 \\
\hline L10 & 2 & 24 & 0.00047 & 0.00316 & 0.00611 & 301.0 & 95.8 \\
\hline L11 & 3 & 4 & \begin{tabular}{|l|}
0.01053 \\
\end{tabular} & \begin{tabular}{|l|}
0.06778 \\
\end{tabular} & \begin{tabular}{|l|}
0.11400 \\
\end{tabular} & \begin{tabular}{|l|}
350.0 \\
\end{tabular} & 74.9 \\
\hline $\mathrm{L} 12$ & 3 & 4 & 0.01280 & 0.05515 & 0.09200 & 301.0 & 61.8 \\
\hline L13 & 3 & 5 & 0.00097 & 0.00548 & 0.02900 & 301.0 & 31.1 \\
\hline L14 & 3 & 6 & 0.00047 & 0.00316 & 0.00477 & 301.0 & 60.9 \\
\hline L15 & 7 & 6 & \begin{tabular}{|l|}
0.00059 \\
\end{tabular} & \begin{tabular}{|l|}
0.00395 \\
\end{tabular} & \begin{tabular}{|l}
0.00636 \\
\end{tabular} & \begin{tabular}{|l|}
301.0 \\
\end{tabular} & 33.6 \\
\hline L16 & 3 & 7 & 0.00121 & 0.00780 & 0.01272 & 301.0 & 41.6 \\
\hline L17 & 12 & 8 & \begin{tabular}{|l|}
0.00227 \\
\end{tabular} & \begin{tabular}{|l|}
0.01517 \\
\end{tabular} & \begin{tabular}{|l|}
0.02449 \\
\end{tabular} & \begin{tabular}{|l|}
301.0 \\
\end{tabular} & 183.6 \\
\hline L18 & 23 & 8 & 0.01427 & 0.07747 & 0.20517 & 350.0 & 218.4 \\
\hline L19 & 9 & 23 & \begin{tabular}{|l|}
0.01427 \\
\end{tabular} & \begin{tabular}{|l|}
0.07747 \\
\end{tabular} & 0.13000 & 350.0 & 159.8 \\
\hline $\mathrm{L} 20$ & 3 & 10 & \begin{tabular}{|l|}
0.01481 \\
\end{tabular} & \begin{tabular}{|l|}
0.06044 \\
\end{tabular} & \begin{tabular}{|l|l|}
0.10338 \\
\end{tabular} & \begin{tabular}{|l|}
301.0 \\
\end{tabular} & \begin{tabular}{|l|}
114.3 \\
\end{tabular} \\
\hline $\mathrm{L} 21$ & 14 & 10 & 0.01304 & 0.05333 & 0.09065 & 301.0 & 119.6 \\
\hline $\mathrm{L} 22$ & 22 & 12 & 0.02153 & 0.13837 & 0.22266 & 350.0 & 125.8 \\
\hline $\mathrm{L} 23$ & 15 & 14 & \begin{tabular}{|l|}
0.00390 \\
\end{tabular} & \begin{tabular}{|l|}
0.01511 \\
\end{tabular} & \begin{tabular}{|l|}
0.02400 \\
\end{tabular} & \begin{tabular}{|l|}
218.0 \\
\end{tabular} & \begin{tabular}{|l|}
52.3 \\
\end{tabular} \\
\hline L24 & 14 & 18 & 0.01779 & 0.05584 & 0.09100 & 162.0 & 89.2 \\
\hline $\mathrm{L} 25$ & 15 & 16 & 0.01073 & 0.04156 & 0.06700 & 218.0 & 94.5 \\
\hline $\mathrm{L} 26$ & 16 & 18 & 0.00801 & 0.05341 & 0.08028 & 301.0 & 136.9 \\
\hline $\mathrm{L} 27$ & 19 & 17 & \begin{tabular}{|l|}
0.00160 \\
\end{tabular} & 0.01106 & 0.01749 & 301.0 & 5.9 \\
\hline $\mathrm{L} 28$ & 19 & 17 & \begin{tabular}{|l|l}
0.00160 \\
\end{tabular} & 0.01106 & \begin{tabular}{|l|}
0.01749 \\
\end{tabular} & \begin{tabular}{|l|}
301.0 \\
\end{tabular} & \begin{tabular}{|l|}
5.9 \\
\end{tabular} \\
\hline L29 & 19 & 18 & 0.00696 & 0.04480 & 0.07500 & 301.0 & 169.7 \\
\hline L30 & 19 & 18 & \begin{tabular}{|l|}
0.01003 \\
\end{tabular} & \begin{tabular}{|l|}
0.04410 \\
\end{tabular} & 0.07101 & 226.0 & \begin{tabular}{|l|}
170.1 \\
\end{tabular} \\
\hline L31 & 21 & 18 & \begin{tabular}{|l|}
0.01695 \\
\end{tabular} & \begin{tabular}{|l|}
0.05546 \\
\end{tabular} & \begin{tabular}{|l|}
0.08931 \\
\end{tabular} & \begin{tabular}{|l|}
187.0 \\
\end{tabular} & \begin{tabular}{|l|}
97.4 \\
\end{tabular} \\
\hline $\mathrm{L} 32$ & 22 & 19 & 0.00251 & 0.01618 & 0.02600 & 350.0 & 117.7 \\
\hline L33 & 23 & 19 & 0.00258 & \begin{tabular}{|l}
0.01659 \\
\end{tabular} & 0.02704 & 350.0 & 114.8 \\
\hline L34 & 23 & 19 & \begin{tabular}{|l|}
0.00258 \\
\end{tabular} & \begin{tabular}{|l|}
0.1576 \\
\end{tabular} & \begin{tabular}{|l|}
0.22139 \\
\end{tabular} & \begin{tabular}{|l|}
350.0 \\
\end{tabular} & \begin{tabular}{|l|}
272.1 \\
\end{tabular} \\
\hline L35 & 21 & 20 & 0.02127 & 0.07376 & 0.12100 & 226.0 & 135.5 \\
\hline L36 & 23 & 20 & 0.02264 & 0.14571 & 0.23538 & 350.0 & 169 \\
\hline L37 & 21 & 22 & 0.01360 & 0.08754 & 0.14200 & 350.0 & 160 \\
\hline
\end{tabular}

Limit of the voltages of nodes and transmissible power :

> The limit of $225 \mathrm{KV}$ voltage is between $202.5 \mathrm{kV}$ and $245 \mathrm{kV}$ that to say is between 0.9 and $1.05 \mathrm{pu}$.

$>$ The limit of transited power in the lines is $0,7 \mathrm{~S}_{\text {limite }}$ lines.

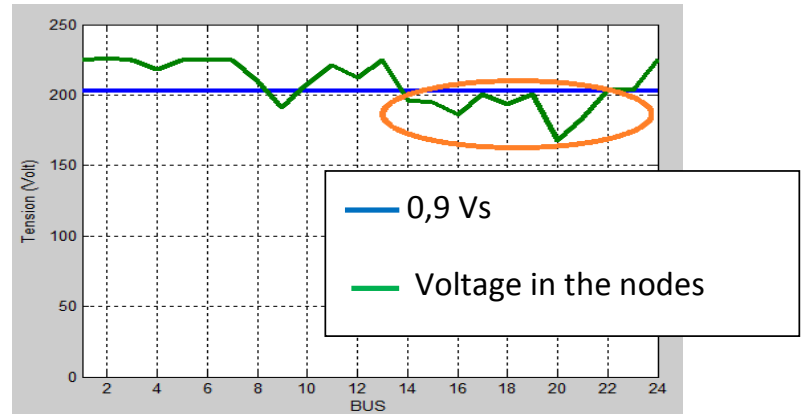

Fig6 : Curve with overruns voltage in the Bus 


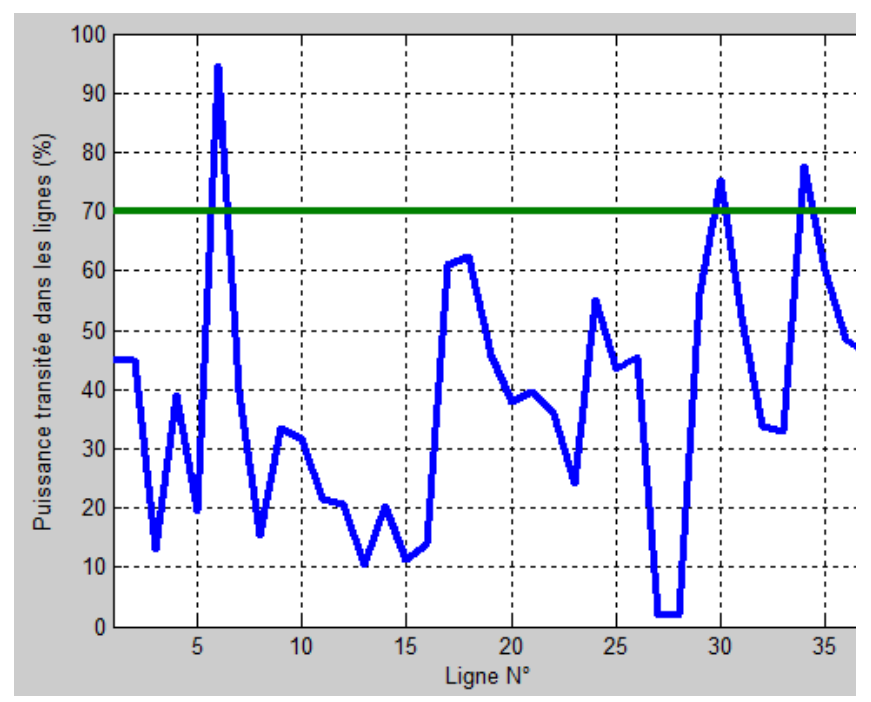

Fig7: Overtaking curve with $70 \%$ of the power limit on lines

Interpretations: The lot of voltage drops that exceed the limit tolerated on busbar $225 \mathrm{kV}$ particular on nodes $14,15,16,17$, 18,19 and 20.

The lines MEDIOUNA - OULADHADDOU; SIDI BENNOUR - GHANEM2; GHANEM - Official Journal LASFAR2, have exceeded over $70 \%$ of the power limit.

Checking the safety rule: In the operation of an electrical system, we are reminded that it is possible at any time that the network or production groups trigger, hence the necessity for the other intact lines can support the failure at some level, by making triggers of the lines, it was found that the onset of the line number 22 and line number 18 causes blackout whence the non-compliance of the rule $\mathrm{N}-1$ [2], [3].

To limit the overtaking power transport lines and to restore the rule of security $\mathrm{N}-1$, we opt for the installation of FACTS on the line number 36 .

It has conducted in parallel a technical-economic study for the choice of the appropriate FACTS device and therefore its contribution to the maintenance of the stability and the good performance of the network. In principle, the TCSC (Thyristor Controlled Series Capacitors) and a capacitor battery are able to overcome these different abnormalities of the network namely by the voltage setting, the distribution of power flow, the improvement of the stability and mitigation of power oscillations while minimizing the cost of investment comparing to the UPFC [1], [4], [5].

Table3: selection criteria of FACTS

\begin{tabular}{|l|c|c|c|c|}
\hline Device & $\begin{array}{l}\text { Control of } \\
\text { power flow }\end{array}$ & $\begin{array}{l}\text { Voltage } \\
\text { Control }\end{array}$ & $\begin{array}{l}\text { transient } \\
\text { stability }\end{array}$ & $\begin{array}{l}\text { static } \\
\text { stability }\end{array}$ \\
\hline SVC & + & +++ & + & ++ \\
\hline STATCOM & + & +++ & ++ & ++ \\
\hline TCSC & ++ & + & +++ & ++ \\
\hline UPFC & +++ & +++ & +++ & +++ \\
\hline
\end{tabular}

So it inserts a TCSC in the line number 36 with parameter compensation by $30 \%$, and capacitor batteries of 14 MVAR in bus number 20 [1], [6], [7].

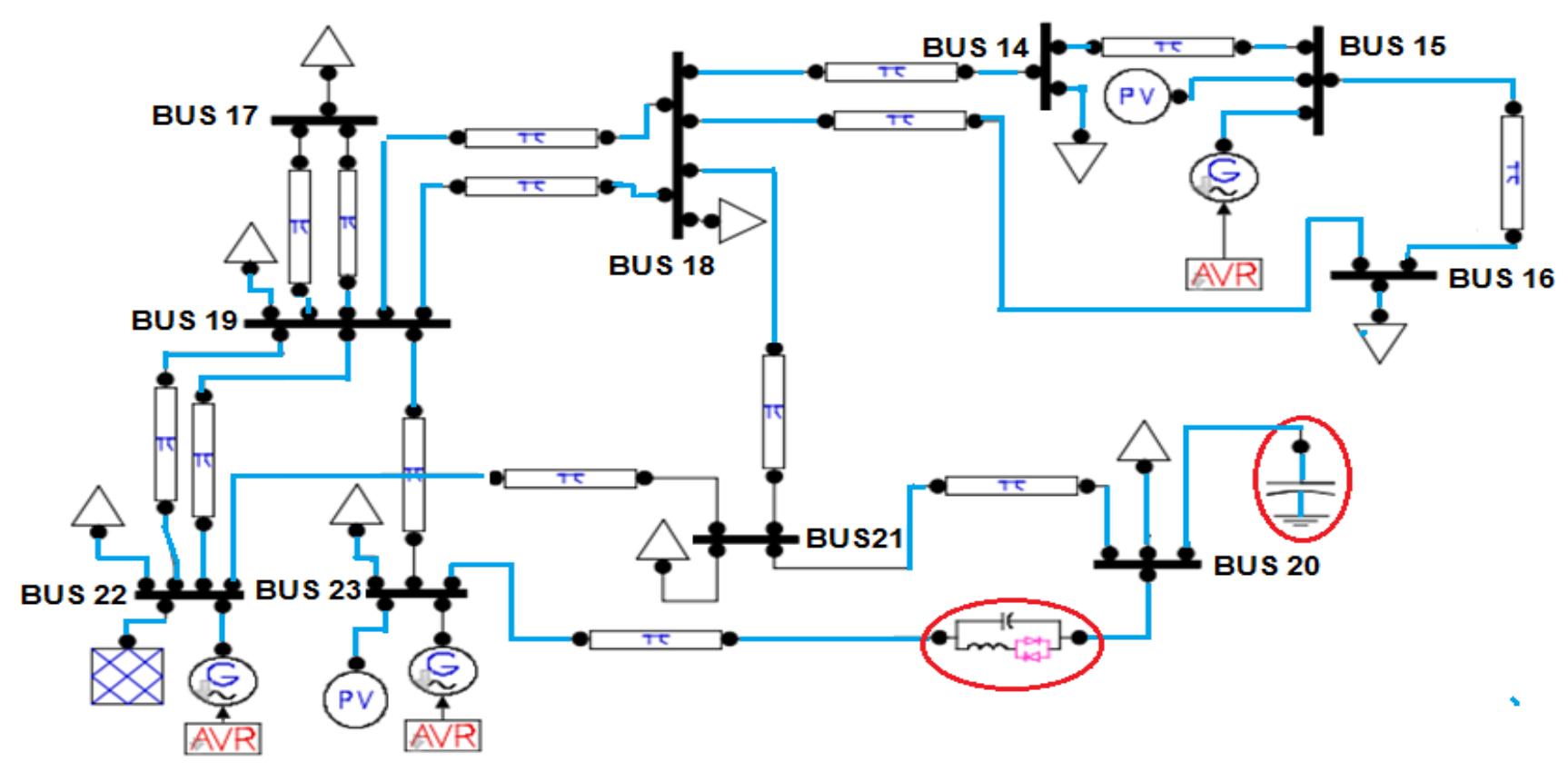

Fig8 : Diagram of the proposed solution in PSAT 
The results obtained before and after the insertion of TCSC and capacitor battery on Bus number 20 .

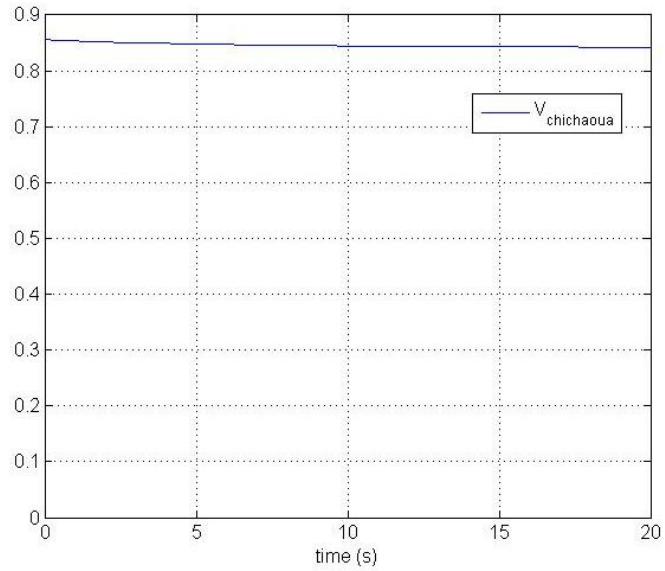

Fig 9: CHICHAOUA bus voltage before correction

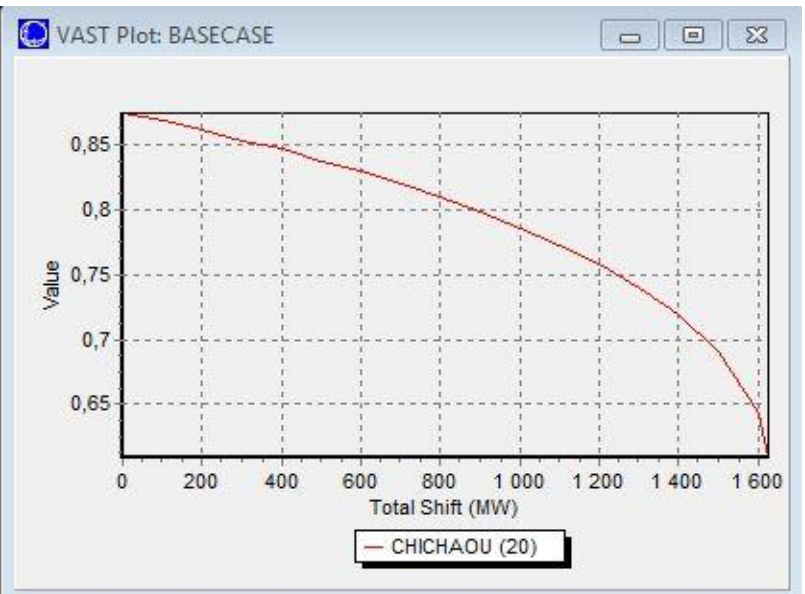

Fig 11 : PV curve before implantation of the TCSC

So there is no more voltage drop on the bus or exceeded $70 \%$ of the power limit lines.

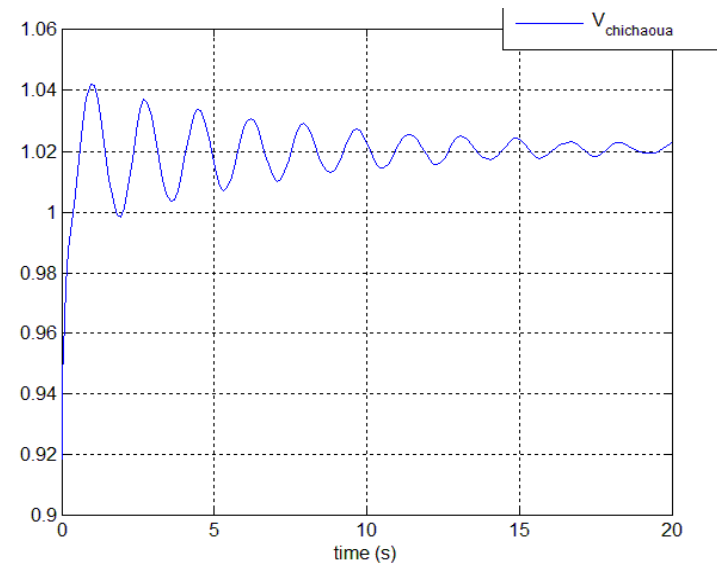

Fig10: CHICHAOUA bus voltage after correction

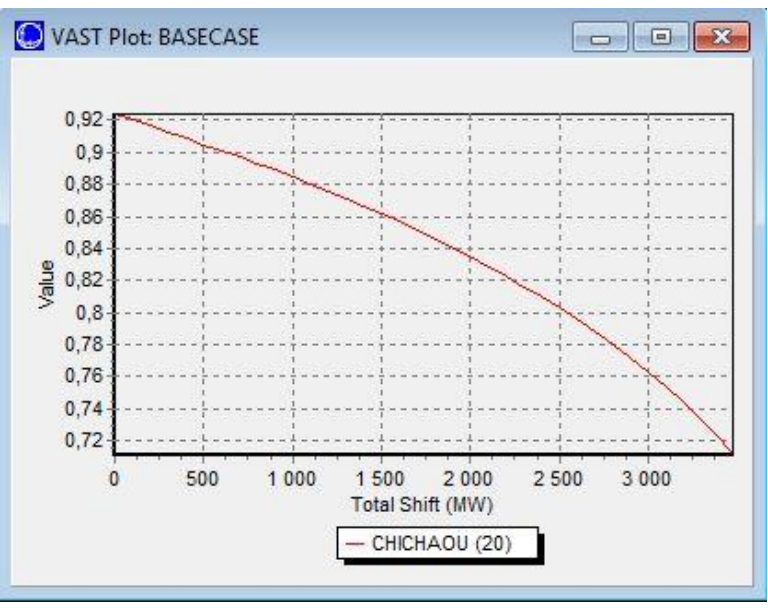

Fig12: PV curve after implantation of the TCSC 
Table 4 - Result of the calculation of the load flow after correction

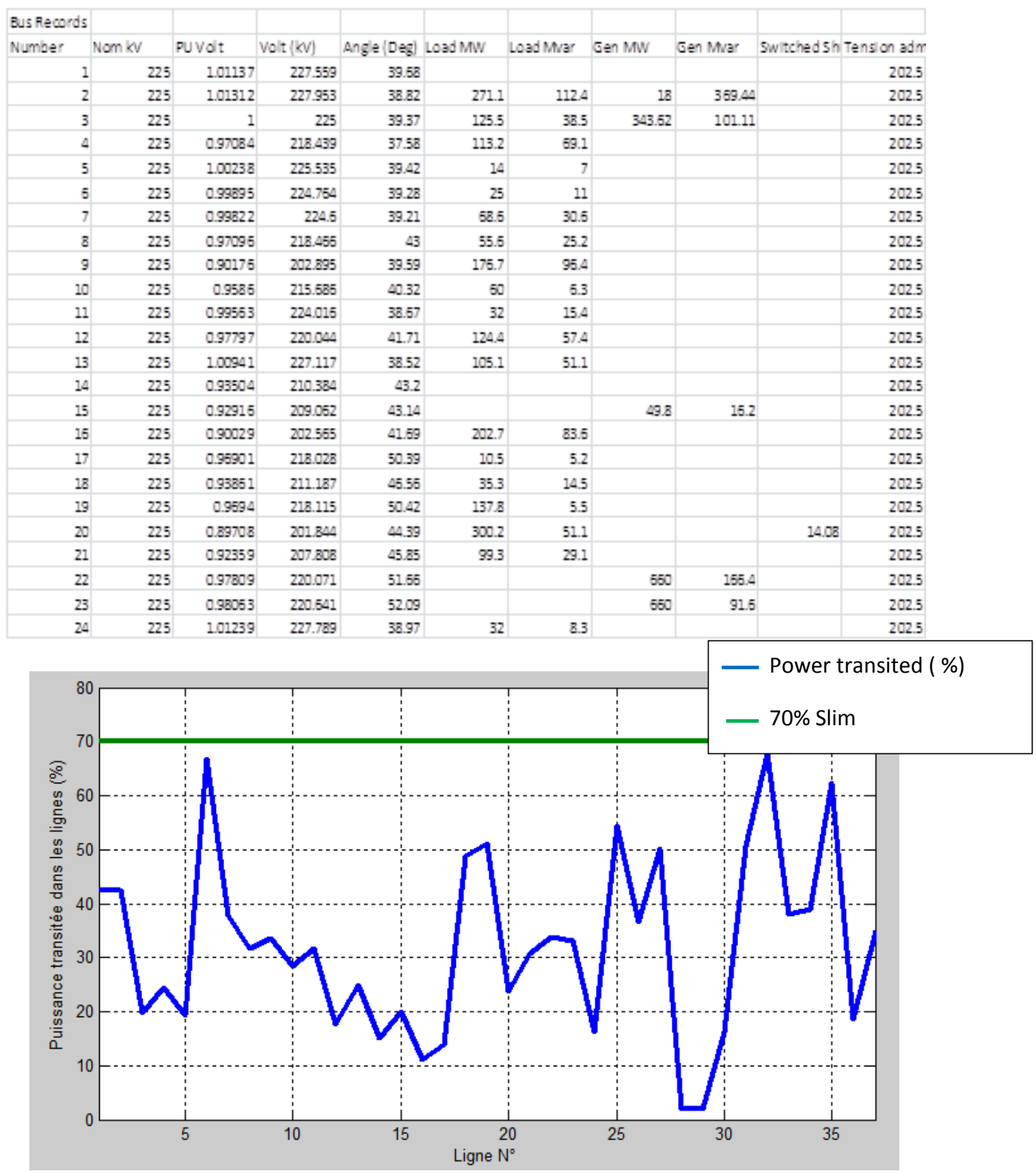

Fig.13- Powers transited through lines after correction

\section{CONCLUSION}

The introduction of TCSC in the network object of study has allowed us to increase the margin stability of the network, it has allowed us to shift the voltage collapse point to increase the value of reactive power, decrease the apparent reactance of the line and thereafter increasing the transport capacity of the power line and to respect the rule N-1.

\section{REFERENCES}

[1] Y. Besanger, "Etude des FACTS (Flexible AC Transmission System) et leur comportement dans les réseaux de transport et d'interconnexion", Thèse de doctorat de l'INPG, 5 Juillet 1996

[2] M. Crappe, "Stabilité et sauvegarde des réseaux électriques", Hermès Science, PARIS, 2003. 
[3] Pierre BORNARD, Michel PAVARD et Georges TESTUD. Réseaux d'interconnexion et de transport : fonctionnement. Techniques de l'ingénieur. [D 4091]

[4] R. Haimour , "Contrôle des Puissances Réactives et des Tensions par les Dispositifs FACTS dans un Réseau Electrique", Thèse de Magister en Electrotechnique, ENSET-Oran,2009
[5] Y. Guo, D.J. Hill and Y. Wang, "Global Transient Stability and Voltage Regulation for Power Systems", IEEE Trans. On Power Systems, vol. 16.

[6] "Utilisation de la compensation série avancée dans les réseaux électriques", Université Djillali Liabes Sidi Bel Abbes, 2008

[7] M. Crappe, "Commande et régulation des réseaux électriques", Lavoisier 2003. 